\title{
GIS-based multi-criteria analysis for land use suitability assessment in City of Regina
}

Jiapei Chen

\begin{abstract}
Background: Land use suitability assessment is a key factor in any urban and suburban planning and decision-making processes. The assessment is evaluated by a series of criteria involving socio-economic needs. To deal with the conflicting, disproportionate and multiple criteria, land usage will be characterized with respect to the preferences and importance. Meanwhile, many spatial decision problems can be typically analyzed and interpreted visually by applying GIS for mapping and analysis. Accordingly, this study is to introduce the Multi-criteria decision analysis into the land use suitability analysis along with the existing perspective evolving the role of GIS.

Results: For case study, it is the first time to conduct the identification of the current land use situations in City of Regina by using GIS, combined with multi-criteria analysis ideology for existing condition analysis with three criteria referring to social and economic factors. Finally, the study identified five suitability levels, which has revealed the trends, challenges and prospects of land use analysis for urban extension in City of Regina.

Conclusion: Comparing the simulated land use suitable classes to the existing land use pattern, difference and optionality have been presented. The results are providing valuable information for the urban extension for policy and decision makers. To improve the accuracy and the reliability of the real-world case study, criteria selection and weight assignments ranks the first place. The integrated use of data analysis and Multi-criteria Decision Analysis approach, in a GIS context, resulted in a visible assessment of current land use in Regina.
\end{abstract}

Keywords: Land use suitability; Multi-criteria decision analysis; GIS; Urban extension; Regina

\section{Background}

Due to the increasing population and economic growth, human activities have continuous impacts on land use. Those impacts might lead to a series complexities toward environment and land resources development (Huang and Xia 2001). Issues related to population and land use competition has emphasized the need for more effective land use planning and policies. In Canada, in particular, the population has been projected to be 47.7 million by 2036 and 63.8 million by 2061, in comparison to 33.7 million in 2009. This pressure of the population will increase the requirement of land use enormously. Land use suitability assessment is to afford a reasonable and sustainable manner for land resource development. Meanwhile, the growing demand for urbanization, land resources used for a variety of purpose will interact and compete with each

Correspondence: jiapeichen88@gmail.com

Faculty of Engineering and Applied Science, University of Regina, S4S OA2 Regina, SK, Canada other. Rational and sustainable decision support based on the land use suitability assessment is an issue of great concern to governments and land users. Thus, an effective way to assess suitability of the current land use and provide policy support to the future land use is desired.

Previously, various methods of spatial analysis for land use are commonly used in the suitability assessment studies. The problem of land use suitability assessment have often been tackled using multi-criteria decision analysis (MCDA) since 1980s (Antoine et al. 1997, Collins et al. 2001, Kiker et al. 2005, Sharifi et al. 2006, Kunwar et al. 2010). Cheng et. al., has reported an integrated MCDA linear programming approach to support selection of an optimal landfill site (Cheng et al. 2003). To create visualized suitability map for users and decision makers, the integration of MCDA and GIS has been widely promoted for solving spatial problems in urban assessment and planning (Phua and Minowa 2005). (Malczewski

\section{黑 Springer}

(C) 2014 Chen; licensee Springer. This is an Open Access article distributed under the terms of the Creative Commons Attribution License (http://creativecommons.org/licenses/by/2.0), which permits unrestricted use, distribution, and reproduction in any medium, provided the original work is properly credited. 


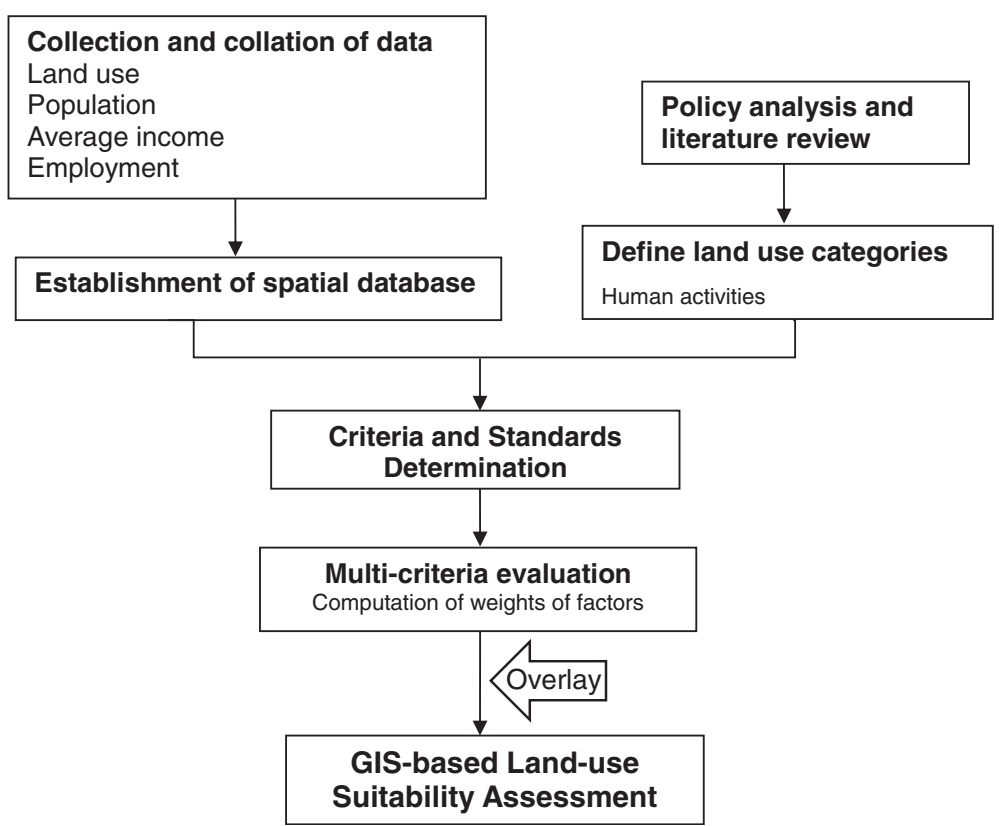

Figure 1 Flowchart of the study.

2006) conducted a survey of literature of the GIS-based Multi-criteria analysis from 1990 to 2004. There has been a substantial acceleration in the number of the GIS-MCDA articles published in this field. Joerin et al. (2001) put forward an outranking multi-criteria analysis method and output a set of land use suitability maps incorporating complex criteria integrating several stakeholders' points of view. Meanwhile, some case studies were performed using the method of integrating GIS and multi-criteria analysis. Hanyang lake area located in Wuhan city, China, was studied with this comprehensive method to analyze the suitability of future land use

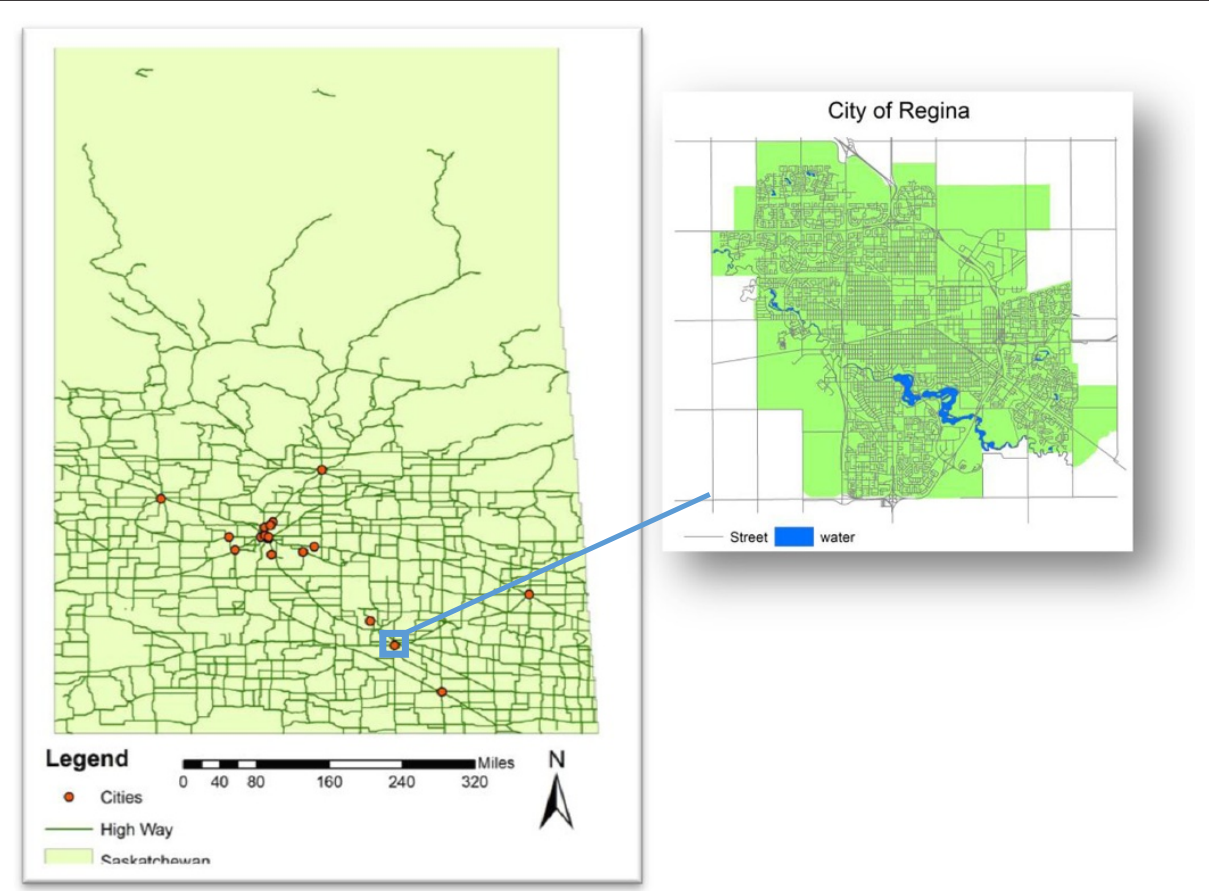

Figure 2 Location of study area and the Saskatchewan Canada. 

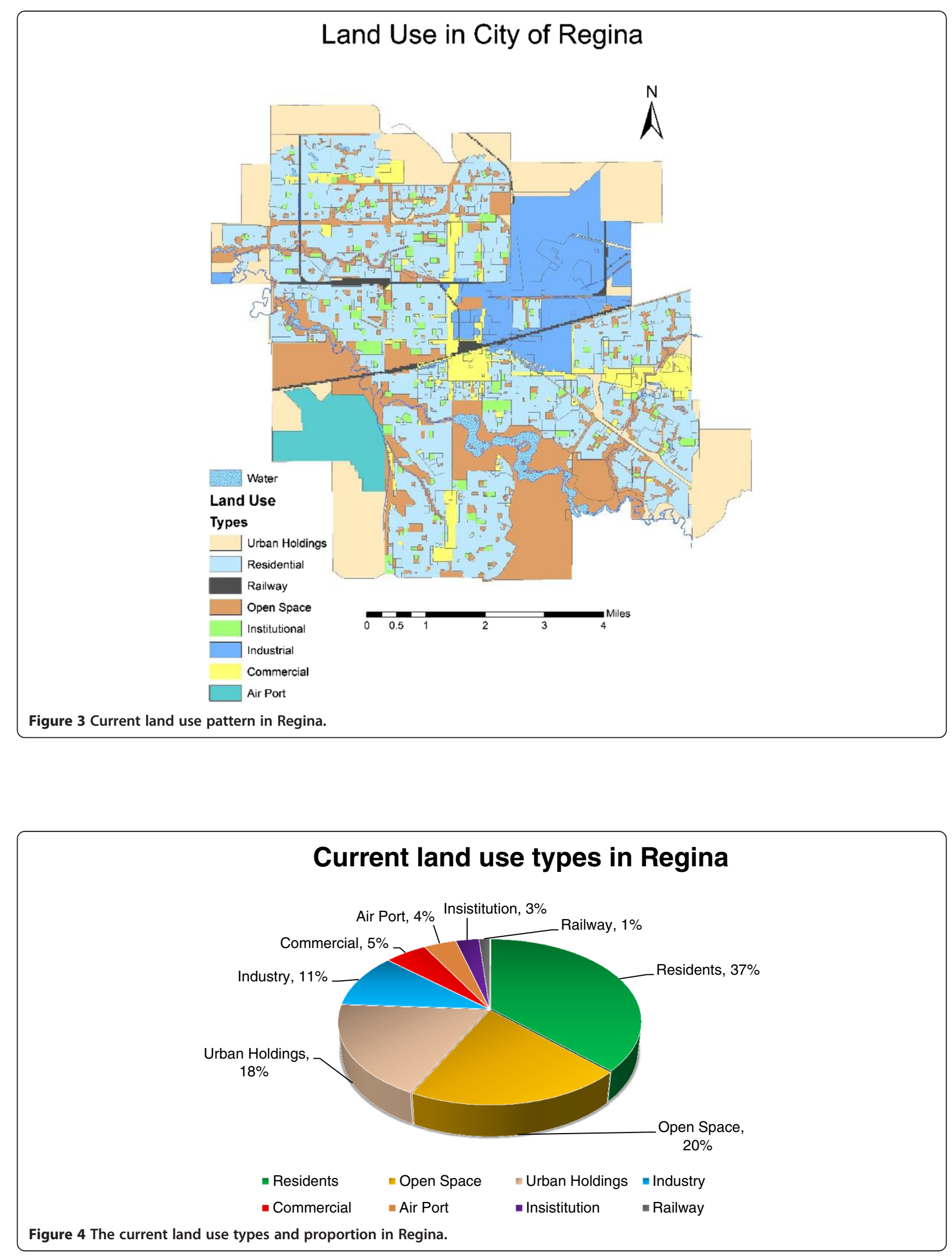


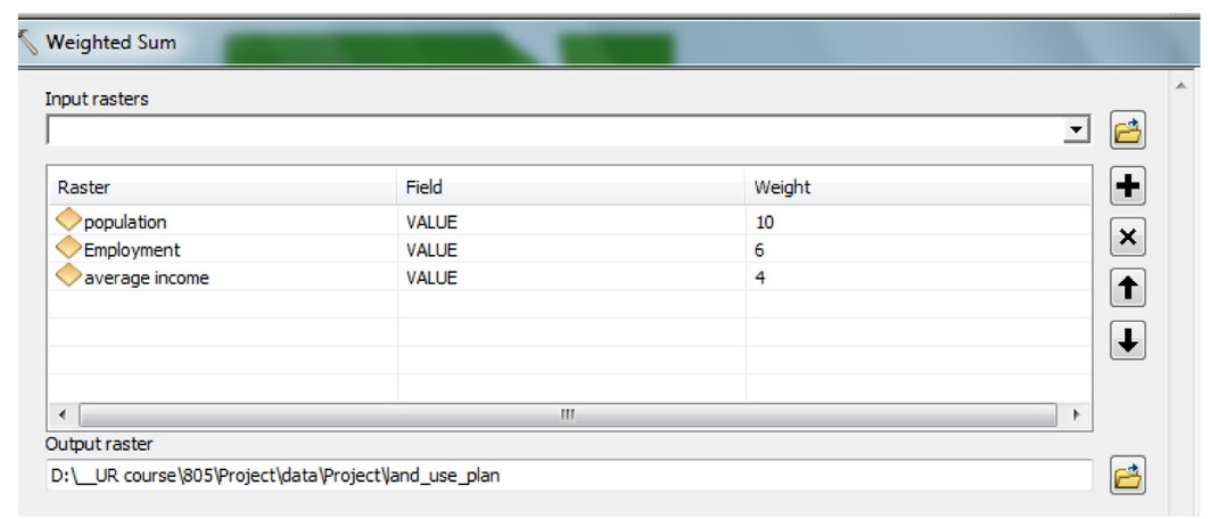

Figure 5 The Multi-criteria Analysis Process.

according to specified requirements, preferences and predictions in Yong Liu et al.'s research (Liu et al. 2007). Dai et al. (2001) conducted a study of the urban land use planning based on GIS and multi-criteria analysis method, which was applied in Lanzhou city, and its vicinity in north-western China.

However, the research has seldom focused on the Prairie Provinces in Canada, especially for the city with less proportion of population. For the further development and urbanization, the land use suitability assessment will play an important role. Thus, the primary aim of this study is to provide recommendation for integrated and sustainable plan for land use development referring to accessibility, economic, integration and environment by means of weighting the selected criteria. Since the required criteria are heterogeneous and measured on various scales in this method. In addition, the data is limited, this research will only analyze the current situation and future exploitation forecasting based on simplified factors, such as population and income.

The assessment is often assessed by a number of criteria. To deal with the inconsistent, incommensurate and multiple criteria, a comprehensive method is needed to analysis the land use scheme under current situation. Then it can be applied to the land use forecasting and planning. The individual criteria will be characterized with respect to the significance and preferences. Meanwhile, spatial decision problems can also be typically analyzed and demonstrated on the base of visualization. Accordingly, the study is to introduce the Multi-criteria decision analysis into the land use suitability analysis along with the existing perspective evolving the role of Geographical Information Systems (GIS).

In this study, the existing land use situation was analyzed and evaluated. Then, based on the analysis the importance of each factor or criterion, the multicriteria analysis system for land use suitability will be applied. Finally, comparison between the existing land use pattern and forecasting land use possibility of the same area will be conducted. The flowchart is shown in Figure 1. Provided data sets in order to generate and store them in a GIS framework, while, as far as the last data sets are concerned, MCDA was involved in the calculation and acquisition in a GIS environment.

\section{The study area}

The study area is the City of Regina, located in southern Saskatchewan, Canada (as shown in Figure 2). The coordinate of the site is $50^{\circ} 27^{\prime} 17^{\prime \prime} \mathrm{N}, 104^{\circ} 36^{\prime} 24^{\prime \prime} \mathrm{W}$. The area of the city is $118.87 \mathrm{~km}^{2}$. Total population of the study area was 179,246 according to census record in 2006. As the capital city of Saskatchewan, city of Regina ranks the second largest in the province, and is a cultural and commercial metropolis in southern Saskatchewan.

The current land use map is presented in Figure 3. There are eight main categories in this study area: Airport, Commerce, Industry, Resident, Institution, Open space, Railway, and Urban holdings. Figure 4 shows the proportion of different land use types. As see form the graph, most of the land in Regina is used as residential area, and then is the open space.

It is reported that strong economic growth has led to employment and population growth in the Population, Employment and Economic Analysis of city of Regina. Thus population, employment and income are chosen as social and economic effect factors. The data source and

Table 1 The weight of each criterion

\begin{tabular}{cc}
\hline Criteria & Wj \\
\hline Population & 10 \\
Employment & 6 \\
Average_income & 4 \\
\hline
\end{tabular}


information are obtained from TerraServer of TERRA Lab, website of Bureau of Saskatchewan and Canada Statistics. On the basis of "A Guide to the Municipal Planning Process in Saskatchewan", a comprehensive policy framework to guide physical, environmental, economic, social, and cultural development in municipality is provided. As social development is one of the most important factors in land use planning, it is considered separately. The data that will be used in the multi-criteria analysis would be related to population, average income of particular census, and employment.

\section{Methods}

Multi-Criteria Decision Analysis (MCDA), developed in the environmental of Operation Research, aids analysts and decision-makers in situations in which there is a need for identification of priorities according to multiple criteria. This usually happens in situations where conflictive interests coexist (Gomes and Lins
2002). MCDA can incorporate both geographical data and stakeholders' preferences into quantified values for assessment and further decisions (Malczewski 2004). The GIS analysis, if integrated with a procedure of data analysis and structuring, can be usefully developed when data are available but the decision context cannot indicate how these data have to be used to produce information and support decisions. The GIS support the solution of complex spatial problems, providing the decision-maker with a flexible environment in the process of the decision research and in the solution of the problem. The visualization of the context, structure of the problem and its alternative solutions is one for the most powerful components of a decision support system (Gomes and Lins 2002). Thus the integration GIS-MCDA has the objective of the supporting decision-makers, providing them with ways to evaluate several alternatives, based on multiple, conflictive criteria.

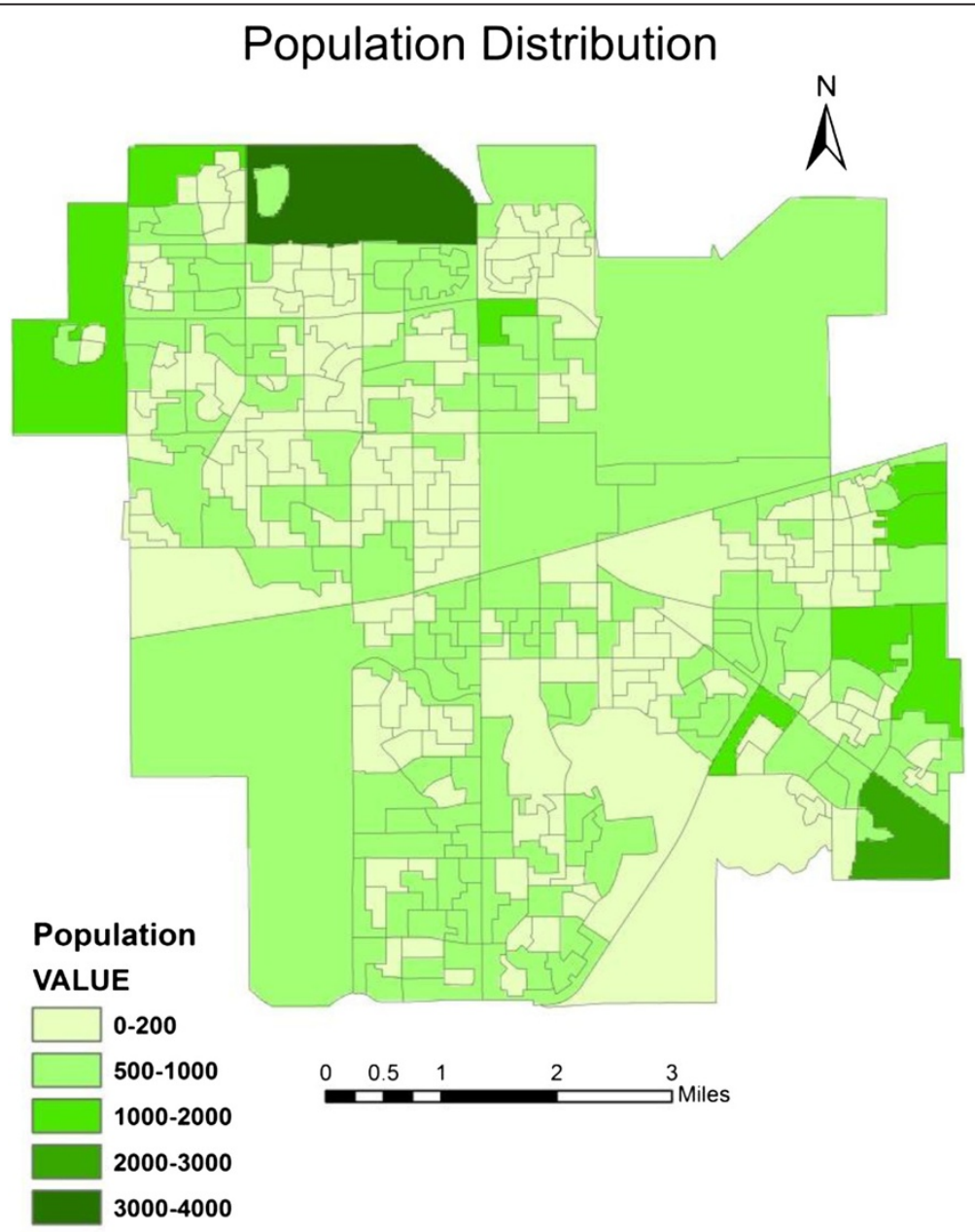

Figure 6 The population distribution of Regina. 
GIS

GIS is a set of tools for inputs, storage and tetrieval, manipulation and analysis, as well as outputs of spatial data (Malczewski, 1999). ArcGIS is acknowledged to be a powerful tool in solving the spatial problems. ArcGIS by ESRI GIS and mapping software was applied for spatial data analysis and mapping in this study. All the related data were collected from Terrasever and Terra lab at University of Regina. Land-use maps and administrative information were input into GIS digitally to establish a new geo-database, then overlapped with each other.

Meanwhile, policy analysis based on community plans and literature reviews were completed, serving as foundation for land use type categories. According to available data, land use for human activity were divided into five suitability levels. In this process, multi-criteria analysis method was used for classifying and weighing criteria. Quantitative analysis is necessary for multi-criteria analysis, including scoring, ranking and weighting.
Finally, an output map of the land use suitability with five classes was displayed and a comparison was conducted between the new land use pattern and the preexisting land use status. The Halme et al. approach introduces the decision-maker's preference in the efficiency analysis, by explicitly locating his most preferred solution vector on the efficient frontier.

The same authors highlight that when systematically exploring the neighborhoods of the Most Preferred Solution (MPS), one does not know explicitly the decision-maker's value function, but its form becomes known when the end of the search for MPS is reached.

\section{Weight product}

Weight product (WP) method has been introduced centuries ago and been advocated in the past few years. WP is a relative simple multiple attribute utility methods. Since WP is easily understood by decision makers and is easy to be conducted, this method have been widely applied in

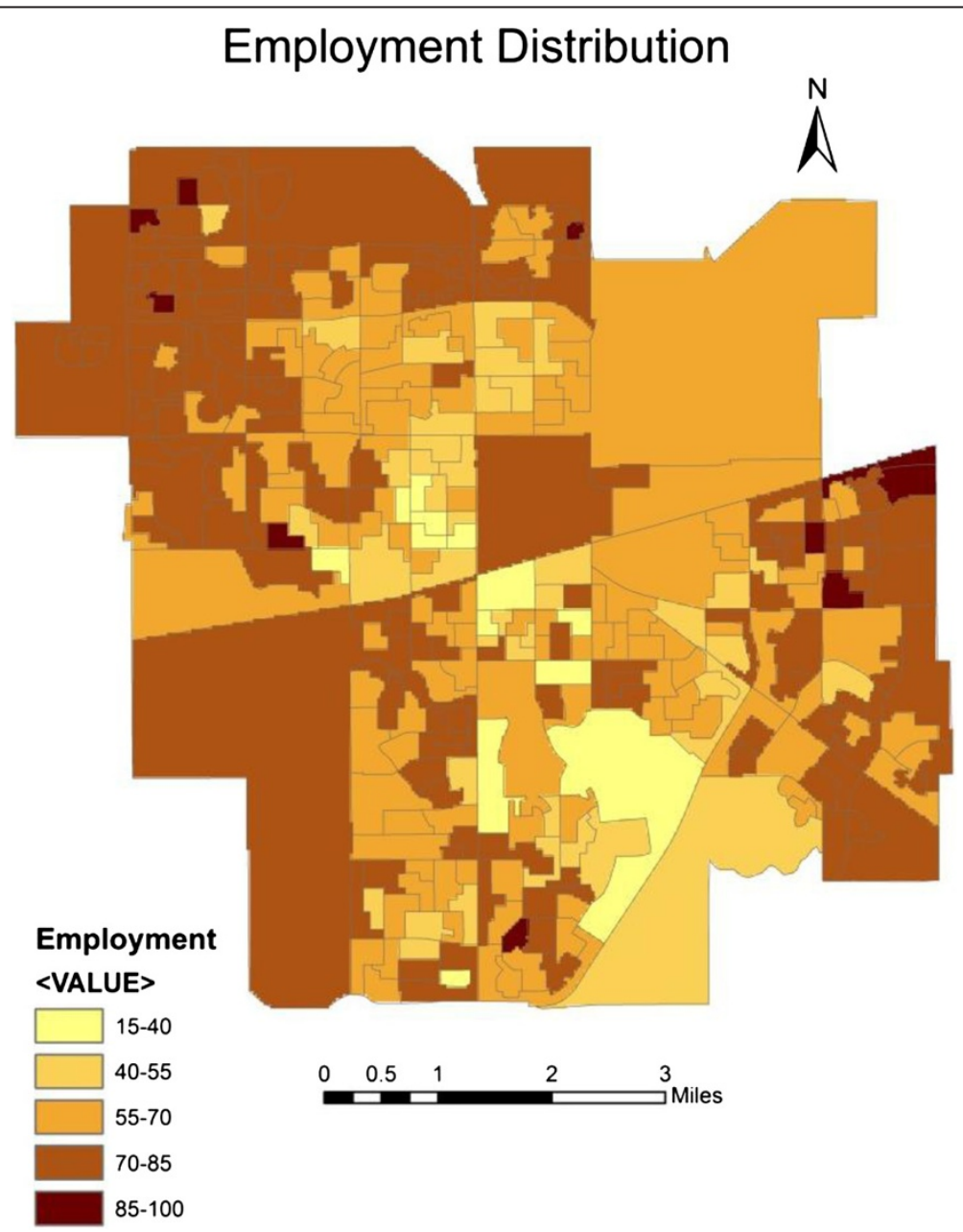

Figure 7 The employment situation of Regina. 


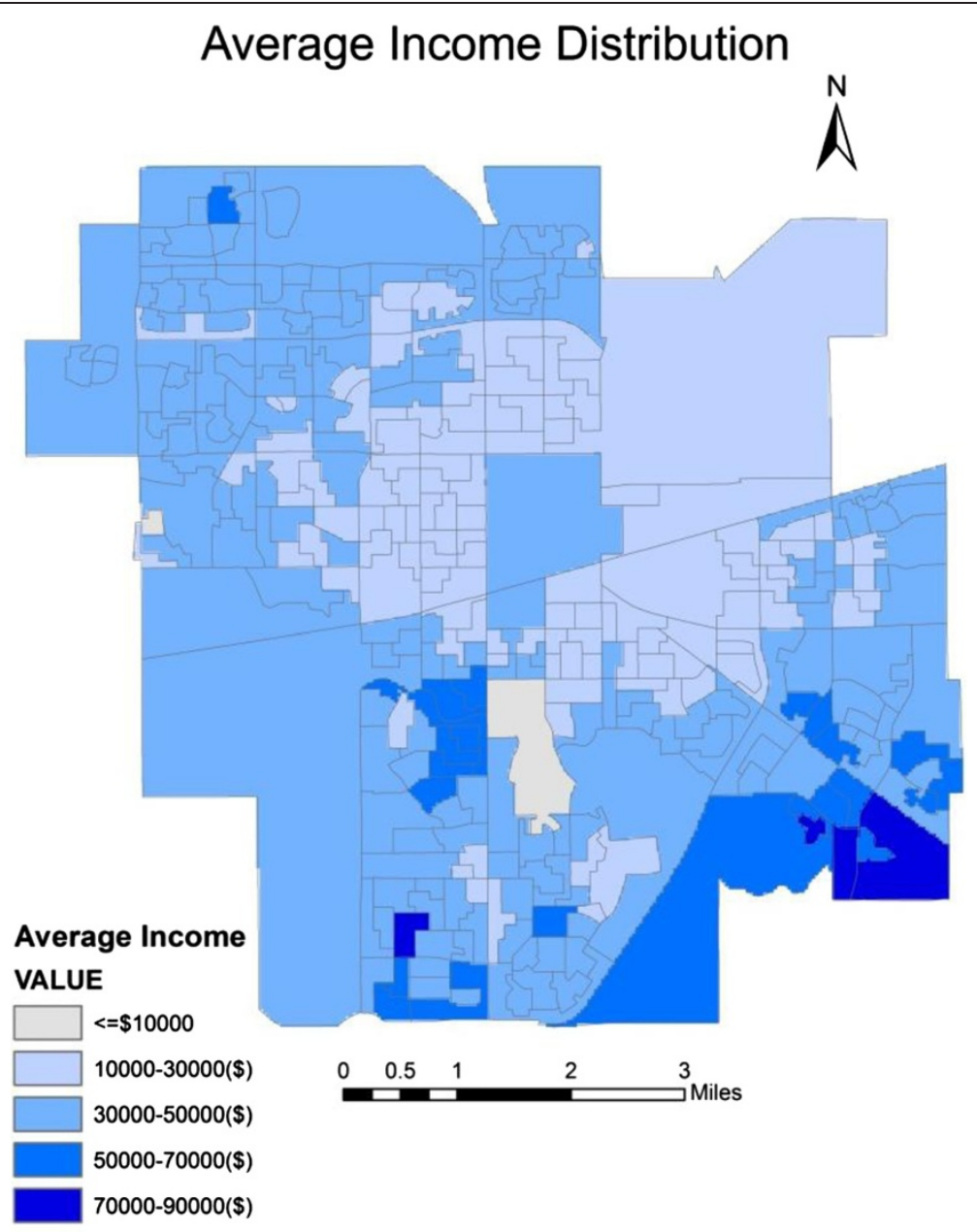

Figure 8 The average income of census.

many fields. In this study, based on the WP method, three factors including population, employment and average income, hold significance in municipal land use planning. In the multi-criteria analysis process as showed in Figure 5, they were assign different weight to obtain a total score of every region based on the following formula (Gomes and Lins 2002):

$$
S_{\mathrm{f}}=\sum_{\mathrm{j}=1}^{3} \mathrm{~W}_{\mathrm{j}} * \mathrm{~A}_{\mathrm{i}}
$$

Where $\mathrm{W}_{\mathrm{j}}$-- is weight of each criterion $\mathrm{j}=1,2, \ldots . \mathrm{m}$, And $\mathrm{A}_{\mathrm{i}}$-is the normalize the value of each grid cell, $\mathrm{i}=1, \ldots . ., \mathrm{n}$.

The general MCAD approach for this case may be seen in (1), where $X_{i}, Y_{i}, \ldots$, represent the value of the criterion $\mathrm{X}, \mathrm{Y} . .$. , for the alternation $\mathrm{i} ; \lambda$ are the decision variables that represent the decision-maker's preferences for the alternative $i, i=1, \ldots, n$. For this case study, $\lambda$ vector representing the decision maker preferences.

$$
\begin{gathered}
\max \sum_{\mathrm{i}=1}^{\mathrm{n}} X_{i} * \lambda_{i} \\
\max \sum_{\mathrm{i}=1}^{\mathrm{n}} Y_{i} * \lambda_{i} \\
\vdots \\
\text { s. } t . \sum_{\mathrm{i}=1}^{\mathrm{n}} \lambda_{i}=1 \\
\lambda \geq 0, \quad i=1, \ldots, n .
\end{gathered}
$$

\section{Defining the criteria}

The expansion of land has overwhelmingly been a response to fast-rising population decades ago, so population is considered the most essential drive force of land exploitation. The weight of each criterion has been shown in Table 1. Meanwhile, as the increasing of urban population, the urbanization of Regina fringe is 
an inevitable trend. Study of population can not only help analysis the existing land use pattern, but also assist land use trend forecasting. Based on the abovementioned consideration, that population is specified the maximum weight among the criteria. The population distribution of Regina is shown in Figure 6.

The employment is expanded to labor force, which is in turn expanded to population equivalents. From a land use point of view, although a city or a region is usually studied as a whole, it is also necessary to examine employment changes brought about by changes in economic. Therefore, employment is defined as a factor in the process of land use or land development. The employment situation of Regina is showed in Figure 7.

Furthermore, as like Hok Lin Leung mentioned that income investigate is essential in house marketing, income is equivalent important in land use planning. The income census of a certain area can reflect the consumption level and trend in a certain extent (Leung 2003). Thus, as one of the economic factor, income is also taken into account when it comes to the land use suitability assessment. The average income of a certain census tract in Regina is showed in Figure 8.

\section{Results and discussion}

After the spatial analysis through ArcGIS, a land use suitable level map was obtained. In this map, the suitability of land use was divided into 5 classes (shown in Figure 9). The most suitable level was defined as the highest score among the weighted values, marking red in the legend. The red areas are in high rate of employment, as well as high income with large population, so they are capable for more human activities area like commercial and residential regions. On the contrary, the least suitable areas were defined to be more suitable for open sources, since there are less human beings and low income or benefit. Based on this interpretation, it could be predicted that the development tendency of Regina would be at north-west and south-east part of the city.

Meanwhile, the current land use map is jointed into the suitability assessment output (Figure 10). Comparison is conducted between these two land use patterns in Table 2. As shown in Table 2, there is a

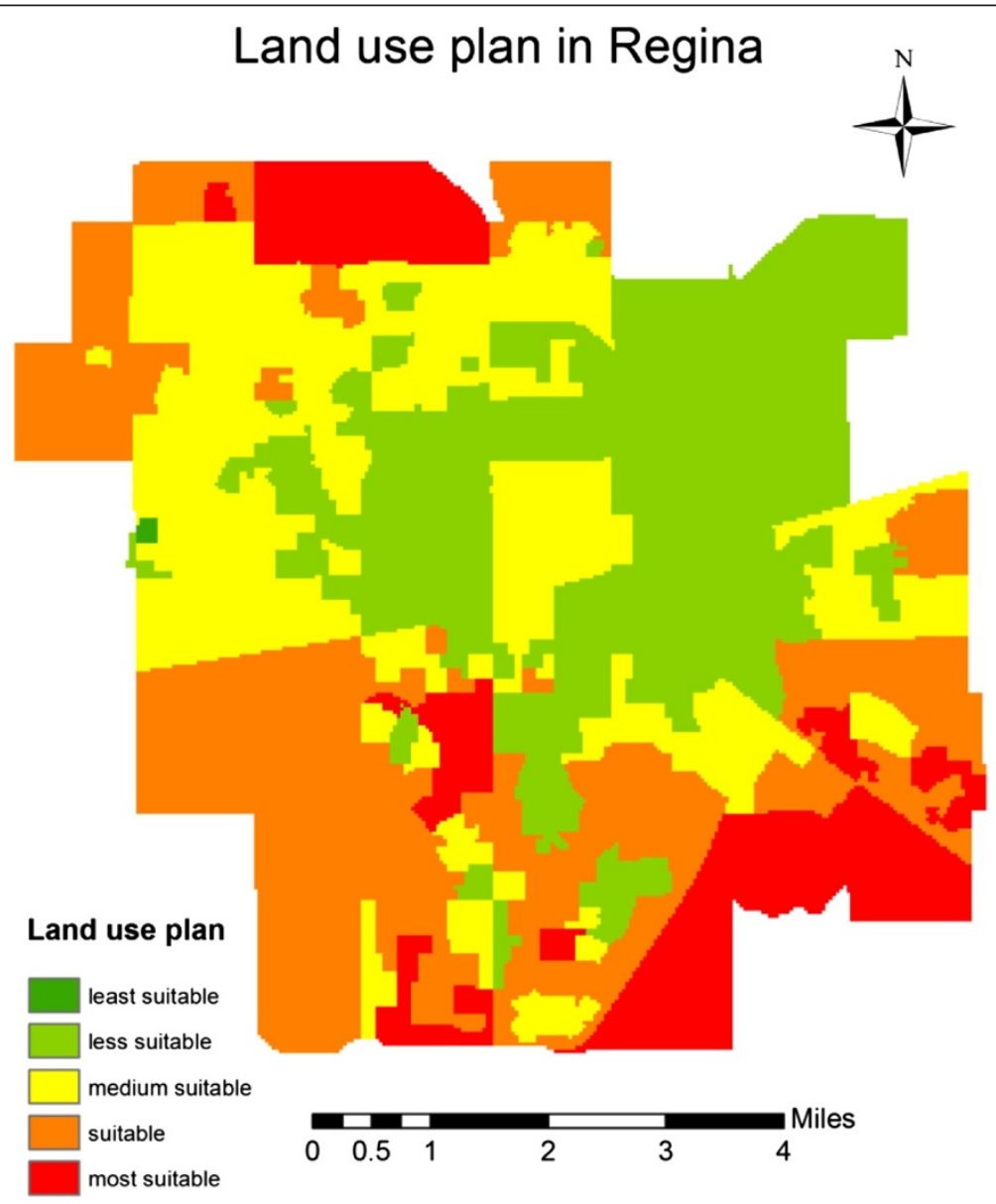

Figure 9 The land use suitability assessment output. 


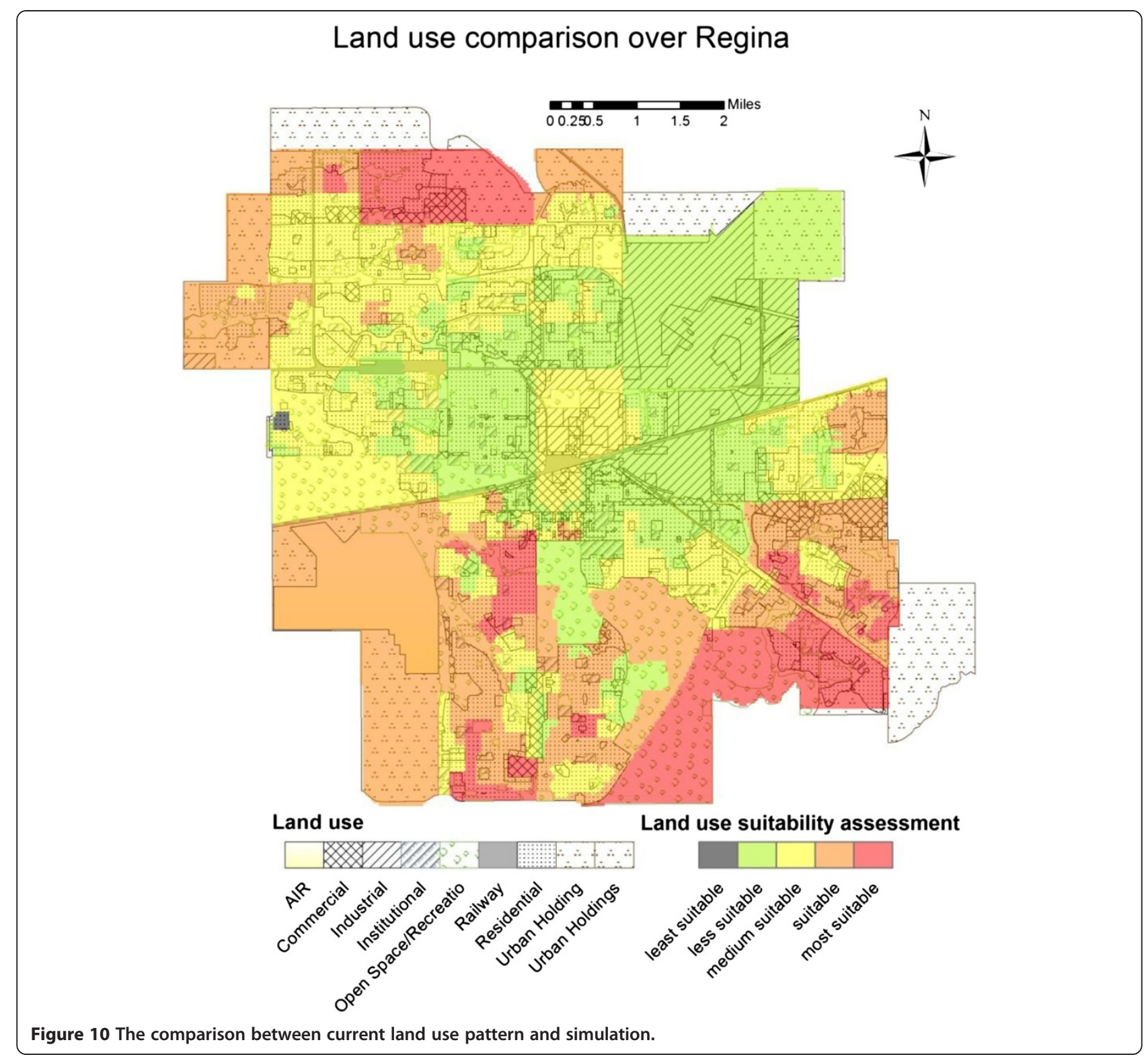

Table 2 The comparison between simulation and actual land use

\begin{tabular}{lll}
\hline Suitable level & Simulation land use & Actual land use \\
\hline Least suitable & Urban holdings & A black spot \\
Less suitable & Air & Industry \\
& Open space/Recreation & Residential \\
Medium suitable & Industry & Residential \\
& Railway & Commercial \\
& & Open space/Recreation \\
Suitable & Commercial & Air \\
& Institutional & Urban holdings \\
Most suitable & Residential & Commercial \\
& & Urban holdings \\
\hline
\end{tabular}

significant distinction between the simulated land use and the actual land use pattern. The results shows that there are significant difference between the simulated land use availability and the existing land use conditions. Although we can say it is not an ideal plan, we can still find and learn something faulty from the process of analysis and make it available to improve in the next time.

In the study, the priority is the criteria selection and determination. In real-world case study, a large number of criteria should be determined, referring to environment, ecology, social and economic. Whilst in this research, only economic factor were considered. This can be considered as a single stage test of the complicated land use plan procedure. Moreover, the weight of criteria should be 
determined by both experts and stakeholders. In this research, the weight was just determined by literal evaluation from municipal land use project plan.

Secondly, the simulation of suitable level is simplified, whilst in the real world, the development pattern is complicated. In the analysis, development scenarios in land use are not easy to pin down. There are no universal rules as to what they should or should not include, and there are no tools available to generate them automatically. F.C. Dai et al. set two scenarios in their study of urban fringe land use planning. One is mainly based on the actual development simulation, and the other scenario is mainly depended on the government planning. Thus, setting scenarios might increase the accuracy of the simulation as well as the reliability.

Moreover, as it is under a small scale analysis, the simplified definition is considered to be acceptable. However, the definition of suitability level results in unprofessional. Take the black spot in the least suitable level for example. It is hard to explain its appearance. It might be assumed to be the fault in the multi-criteria analysis procedure. And beyond the public opinion survey and social investigation, the suitability assessment seems to be groundless. Thus, the result might be better if the operational research is implemented in the future study.

\section{Conclusion}

Assessing the land use development problem has become an important task under the increasing aware of land resource conservation. Land use suitability assessment is a practical tool to make decision on land use development. However, less works could be found that use quantized index to evaluate the land resource usage at Prairie Provinces in Canada. This study applied GIS combined with multi-criteria decision analysis ideology in the City of Regina to assess land use condition with three important criteria referring to social and economic. Finally, a map with five suitability levels can be obtained.

When comparing the simulated land use suitable classes with the existing land use pattern, we can find that: the significant differences between these two land use patterns reflect the limitation of the approach and data availability. Two possibilities are put forward to increase the reliability and accuracy of land use suitability assessment, where the research is potentially valuable. Urban land use categories are complicated process. Recommendations made for future studies is to improve the efficacy and objectivity of local land use evaluation to support the land use suitability assessment and avoid the subjectivity. As for the accuracy of the real-world case study, the criteria selection and the weight assignment should be widely and deeply discussed and researched.

The results represent the potential of GIS-based evaluation for urban planning purpose. However, it needs to be emphasized that the reliability of the assessment results depends on a multitude of factors ranging from the quality of the database to the potential errors in the GIS. Meanwhile, the modeling results are highly significant to the weights applied. The determination of a multitude of factors and weights for the various factors is one of the most important challenges in the future.

\section{Competing interests}

The author declares that she has no competing interests with anyone.

\section{Author's contributions}

JC carried out the data collection, methods, results analysis and finish the manuscript.

\section{Acknowledgement}

This research has been conducted within University of Regina. The Terrasever and Terra lab provided the equipment and materials for this research. This research is also supported by Dr. Joe Piwowar in the data collection and Dr. Gordon Huang.

Received: 12 December 2013 Accepted: 11 March 2014

Published: 2 July 2014

\section{References}

Antoine J, Fischer G, Makowski M (1997) Multiple criteria land use analysis. Appl Math Comput 83:195-215

Cheng S, Chan CW, Huang GH (2003) An integrated multi-criteria decision analysis and inexact mixed integer linear programming approach for solid waste management. Eng Appl Artif Intel 16(5):543-554

Collins M, Steiner F, Rushman M (2001) Land-use suitability analysis in the United States: historical development and promising technological achievements. J Environ Manage 28(5):611-621

Dai F, Lee C, Zhang X (2001) GIS-based geo-environmental evaluation for urban land-use planning: a case study. Eng Geol 61(4):257-271

Gomes E, Lins M (2002) Intergrating geographical information systems and multi-criteria methods: a case study. Ann Oper Res 116:243-269

Huang G, Xia J (2001) Barriers to sustainable water-quality management. J Environ Manage 61:1-23

Joerin F, Thériault M, Musy A (2001) Using GIS and outranking multicriteria analysis for land-use suitability assessment. Int J Geogr Inf Sci 15(2):153-174

Kiker G, Bridges T, Varghese A, Seager T, Linkov I (2005) Application of multicriteria decision analysis in environmental decision making. Integr Enviro Assess Manage 1(2):95-108

Kunwar P, Kachhwaha T, Kuma A, Agrawal AK, Singh A, Mendiratta N (2010) Use of high-resolution IKONOS data and GIS technique for transformation of landuse/landcover for sustainable development. Curr Sci India 98(2):204-212

Leung H (2003) Land use Planning Made Plain. University of Toronto Press, Toronto, Canada

Liu Y, Lv X, Qin X, Guo H, Yu Y, Wang J, Mao G (2007) An integrated GIS-based analysis system for land-use management of lake areas in urban fringe. Land Scape Urban Plan 82(4):233-246

Malczewski J (1999) GIS and multicriteria decision analysis. John Wiley \& Sons.

Malczewski J (2004) GIS-based land-use suitability analysis: a critical overview. Pro Plann 62(1):3-65

Malczewski J (2006) GIS-based multicriteria decision analysis: a survey of the literature. Int J Geogr Inf Sci 20(7):703-726

Phua M, Minowa M (2005) A GIS-based multi-criteria decision making approach to forest conservation planning at a landscape scale: a case study in the Kinabalu Area, Sabah, Malaysia. Land Scape Urban Plan 71(2):207-222

Sharifi M, Boerboom L, Shamsudin K, Veeramuthu L (2006) Spatial Multiple Criteria Decision Analysis in Integrated Planning for Public Transport and Land use Development Study in Klang Valley, Malaysia. ISPRS Technical Commission 2nd Symposium, United States, pp 85-91

doi:10.1186/2193-2697-3-13

Cite this article as: Chen: GIS-based multi-criteria analysis for land use suitability assessment in City of Regina. Environmental Systems Research 2014 3:13. 